\title{
Surface Modification of Carbon Nano tubes with Nystatin for Drug Delivery Applications
}

\author{
Pravin Shantaram Uttekar*, Akshata Malhari Kulkarni, Pravinkumar Namdeorao Sable, Praveen \\ Digambar Chaudhari
}

Progressive Education Society's Modern College of Pharmacy, Sector no. 21, Yamunanagar, Nigdi, Pune-44, Maharashtra, INDIA.

\begin{abstract}
The present study is an approach to describe the increased antifungal efficacy of Nystatin by conjugation with functionalized multi-walled carbon nano tubes. Functionalized Multi-walled carbon nano tubes are acts as nano vectors for the delivery of therapeutic molecules by conjugation. Structural properties of carbon nano tubes have emerged as a new alternative and efficient tool for transporting and translocating therapeutic molecules to target moieties. Carbon nano tubes are easily cross cell membranes delivered drug molecules into fungal cells. Nystatin, most effective antibiotic in the treatment of fungal infections. Carbon nano tubes oxidized using strong acids (3:1 Ratio of Concentrated Sulphuric and Nitric acid), resulting in the reduction of their length while generating carboxylic groups, which increase their dispersibility in aqueous solutions. Oxidised CNTs are then functionalized by direct coupling of Ethylene-diamine with carboxylic groups cited at external walls to introduced amino group via amide formation. Nystatin, most effective antibiotic is conjugated with CNTs via two step process of diamide-activated amidation. Fourier-transform infrared spectroscopy (FT/IR), UV-Visible Spectroscopy, Scanning Electron Microscopy (SEM), \& Transmission Electron Microscopy (TEM) measurements clearly confirmed the functionalization \& conjugation steps.
\end{abstract}

Key words: Multi-walled carbon nanotubes, Nystatin, Antifungal, Surface Modification, Conjugation.

\section{INTRODUCTION}

The search for new and effective drug delivery systems is a fundamental issue of continuous interest. CNTs (Carbon nano tubes) are unique, one-dimensional macromolecules. ${ }^{1}$ SWCNTs (Single-walled carbon nano tubes) are constructed of a single sheet of graphite (diameter 0.4-2 nm), while MWCNTs (multi-walled carbon nano tubes) consist of multiple concentric graphite cylinders of increasing diameter of (2-100 nm). One of the major areas of CNTs research is the field of biomedical materials and devices. Many applications for CNTs have been proposed including biosensors, drug and vaccine delivery vehicles and novel biomaterials. $^{2}$ Nanotechnology has nearly limitless potential in biomedical applications. ${ }^{3,4}$ Nano particle, among all available drug carri- ers gain more attractive attention; since they can be so manipulated that remains in circulation system to reach the diseased site and can penetrate through the cell membrane..$^{3-5}$ Carbon nano tubes possess the capacity of penetrating the blood-brain barrier without causing the death of a living cell or without inflicting other damage. Carbon nano tubes, originally discovered by Iijima in 1991, are structures made up of thin sheets of benzene ring carbons rolled up into the shape of a seamless cylinder and are often capped on at least one end by a spherical bucky ball structure. ${ }^{6,7}$ In order to modify carbon nano tubes which increase their biocompatibility and solubility profile, different fictionalization approaches will apply to CNTs. ${ }^{6}$ Therefore,
Submission Date :07-01-2016 Revision Date : :29-02-2016 Accepted Date : :13-03-2016

DOI: $10.5530 /$ ijper.50.3.10 Correspondence Dr. Pravin Shantaram Uttekar

Progressive Education Society's,

Modern College ofPharmacy, Sectorno21, Yamunanagar, Nigdi, Pune, Maharashtra, INDIA.

Mobile:+91-9545452765

E-mail ld-pravinsuttekar@ yahoo.co.in

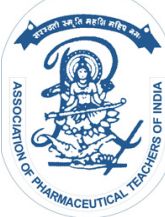

www.ijper.org 
fictionalization of carbon nano tubes is a key step for further their application. ${ }^{7}$ The oxidative reactions are widely employed for chemical modification of CNTs which generate carboxylic groups to the tips and defect sites of CNTs. ${ }^{8}, 9$ These functional groups can further attached to other reactive groups or biological molecules such as drugs and used to deliver their cargos to cells and organs. ${ }^{10,11}$

\section{Experimental Materials}

The following chemicals were obtained from commercial suppliers and used as received: Nystatin (Maneesh Pharmaceuticals Pvt. Ltd., Mumbai.), carbon nano tubes (Applied science Innovations Pvt. Ltd., Pune.), N-ethylN'-(3-dimethyl-aminopropyl) Carbodimide hydrochloride (EDAC) (Sisco Research Lab. Pvt. Ltd., Mumbai.), N-hydroxysuccinimide (NHS) (Sisco Research Lab. Pvt. Ltd., Mumbai.), 2-(N-morfolino) ethanesulfonic acid (MES) (Sisco ResearchLab. Pvt.Ltd., Mumbai.), Ethylenediamine (Thermo Fisher Scientific India Pvt. Ltd., Mumbai.), Concentrated $\mathrm{H}_{2} \mathrm{SO}_{4}$ (Hexon Laboratries Pvt. Ltd., Pune.) and Concentrated $\mathrm{HNO}_{3}$ (Qualigens Fine Chemicals, Mumbai.).

\section{Method}

\section{Oxidation of carbon nano tubes}

MWCNTs expose to oxidative conditions, i.e. $150 \mathrm{mg}$ of MWCNTs were treated with 3:1 mixture of concentrated sulphuric acid \& nitric acid. This mixture was then sonicated (Ultrasonic Probe Sonicator, DP-120) simultaneously irradiated with varying amplitudes of ultrasonic energy up to $10 \mathrm{hrs}$. A probe has a tip diameter of 13 $\mathrm{mm}$ and is immersed $5 \mathrm{~mm}$ in the liquid. The device operates at a fixed wavelength of $20 \mathrm{kHz}$ and is capable of inducing a maximum power output of $750 \mathrm{~W}$. Upon completion, the mixture was washed with cold distilled water to remove the residual acid and then centrifuged at $3000 \mathrm{rpm}, 4^{\circ} \mathrm{C}$ (Cryocentrifuge 2810R, Eppendorf, USA) until the supernatant of the mixture represents the $\mathrm{pH}=7$ which exhibit absence of acid residues in the suspension. Sample was then dried in vacuum (Krishna Technocreats, Basic) and kept in oven at $80^{\circ} \mathrm{C}$ for $4 \mathrm{hr}$.

\section{Functionalization of carbon nano tubes with ethylene-diamine}

$150 \mathrm{mg}$ of the oxidized nano tubes was dispersed by sonication in $75 \mathrm{~mL}$ of ethylenediamine. $7.5 \mathrm{mg}$ of the EDAC was then added and sonicated (Ultrasonic Probe Sonicator, DP-120) for $4 \mathrm{~h}$. The product was then diluted with excess methanol and centrifuged
(Centrifuge Apparatus, RM-E2) to remove excess materials. The functionalized CNTs were then dried in a vacuum (Krishna Technocreats, Basic) oven at $80^{\circ} \mathrm{C}$ for $4 \mathrm{hr}$.

\section{Two step conjugation process of Nystatin to carbon nano tubes}

\section{a. Step - I}

$10 \mathrm{ml}$ of $250 \mu \mathrm{g} \mathrm{ml}^{-1}$ Nystatin solution was re-dispersed in $4 \mathrm{ml}$ of $500 \mathrm{mM}$ MES buffer solution followed by addition of $9.2 \mathrm{ml}$ of $50 \mathrm{mg} \mathrm{ml}^{-1}$ NHS solution and mixed with fast stirring (Mechanical Stirrer, Omega Scientific Industries). Then add $4.8 \mathrm{ml}$ of $10 \mathrm{mg} \mathrm{ml}^{-1}$ fresh EDAC aqueous solution quickly. Solution or mixture was continually stirred at room temperature for 30 min (Figure 1).

\section{b. Step - II}

Amide functionalized CNTs were re-dispersed in $90 \mathrm{ml}$ of MES $50 \mathrm{mM}$ buffer solution $(\mathrm{pH}=6.1)$ then above solution was added. After addition of above solution, nano tubes mixture was kept on platform shaker (Orbital Shaker, RIS-24BL) at $120 \mathrm{rpm}$ at room temperature for 90 minutes. After shaking the mixture, the nano tubes suspension was then centrifuged (Centrifuge Apparatus, RM-E2) and wash with $50 \mathrm{mM}$ MES buffer solution $(\mathrm{pH}=6.1)$ three times to remove unbound Nystatin (Figure 1).

\section{Characterization of conjugated MWCNTs with Nystatin}

\section{Fourier-transform infrared (FTIR) Spectroscopy}

IR spectra were measured with a Bruker Equinox 55S IR spectrometer, in the region of $400-4000 \mathrm{~cm}^{-1}$ with a resolution of $4 \mathrm{~cm}^{-1}$, equipped with a DTGS detector. Each spectrum was the average of 200 scans collected at $2 \mathrm{~cm}^{-1}$ resolution.

\section{UV-Vis Spectroscopy}

The UV-Visible Spectrum of Pure Nystatin, f-MWCNTs, Nystatin conjugated to MWCNTs \& unbound MWCNTs molecules were obtained in mixture of Glacial acetic acid \& methanol (1:1 ratio). Samples were scanned over the range of $200-400 \mathrm{~nm}$ by using UV-Visible spectrophotometer (Jasco-1800).

\section{Scanning Electron Microscopy (SEM)}

Electron micrograph of Nystatin conjugated MWCNTs was obtained using a scanning electron microscope (JEOL JSM-5200) operating between 5 and $24 \mathrm{kV}$. 


\section{Transmission Electron Microscopy (TEM)}

The size and morphology of the conjugated MWCNTs were characterized by a Philips CM-100 TEM equipped with Hamamatsu Digital Camera ORCA-HR operated using AMT software (Advanced Microscopy Techniques Corp, Danver, MA).

\section{Ex-vivo Study: Minimum Inhibitory Concentration}

Carbon nano tubes conjugated Nystatin was dissolved in dimethyl sulfoxide (DMSO)/absolute ethanol (at a ratio of 3:2), to an initial concentration of $10,000 \mu \mathrm{g} / \mathrm{ml}$ and stored at $-20^{\circ} \mathrm{C}$ until used.

Bacterio static and bactericidal activities of nystatin towards Candida albicans, Candida parapsilosis and Candida neoformans were determined by the broth dilution technique as per McGinnis and Rinaldi (1996). Briefly, $50 \mu$ of the Carbon nano tubes conjugated Nystatin was two-fold serially diluted with Sabouraud-dextrose broth in a microtitre plate. An equal volume of yeast suspension $(9 \times 107$ cells $/ \mathrm{ml})$ was added and mixed with the drug. DMSO/absolute ethanol (3:2 ratio) without nystatin was used as the control. The minimum inhibitory concentration (MIC) was determined visually following $24 \mathrm{~h}$ incubation at $37^{\circ} \mathrm{C}$ for $2-3$ days. The MIC was defined as the lowest concentration of the drug that inhibited growth of yeast cells, as indicated by the absence of turbidity (optically clear). Subculturing from the optically clear/turbid wells was performed to determine the minimum fungicidal concentration (MFC). The subcidal concentration of nystatin for all strains, used as positive control, in this study was the concentration slightly below the MFC of the drug.

All experiments were repeated on two separate occasions, with duplicate determinations on each occasion.

\section{RESULTS AND DISCUSSION}

The IR spectrum of the pure MWCNTs (Figure 2A) showed the characteristic stretching vibrations of $\mathrm{O}-\mathrm{H}$ groups at $3400 \mathrm{~cm}^{-1}$. Peak at $1720 \mathrm{~cm}^{-1}$ appears in the spectrum of the oxidised MWCNTs (Figure 2B) is attributed to the $\mathrm{C}=\mathrm{O}$ stretch of the carboxylic group $(\mathrm{COOH})$ after the oxidation process on the surface of the oxidised MWCNTs. The FT/IR spectrum of a amide-functionalized MWCNTs (Figure 2C) shows the disappearance of a band at $1720 \mathrm{~cm}^{-1} \&$ appearance of a band with a lower frequency at $1661 \mathrm{~cm}^{-1}$ attributed the amide carbonyl $(\mathrm{C}=\mathrm{O})$ stretch. Also, presence of new band at $1523 \mathrm{~cm}^{-1}$ assigned to an $\mathrm{N}-\mathrm{H}$ in-plane \& at $1223 \mathrm{~cm}^{-1}$ arise from C-N band stretching. This confirms the presence of the amide functional group. ${ }^{12}$
Figure 3 shows the UV-visible spectra of the pure Nystatin, functionalized MWCNTs, conjugated MWCNTs and unbound Nystatin. The pure Nystatin display absorption peaks in range of $275 \mathrm{~nm}$ to $325 \mathrm{~nm}$ (Curve A), which is typical for Nystatin. These characteristic absorption peaks (Curve C) at range of $275 \mathrm{~nm}$ to $325 \mathrm{~nm}$ was also appear in the spectrum of conjugated MWCNTs confirms the conjugation of Nystatin with MWCNTs. The UV-visible spectra (Curve D) of supernatant of centrifuged solution which contains unbound Nystatin further confirms modification. From the UV/Vis Result, this confirmed that successful conjugation of nystatin molecule to MWCNTs. This implies that the Nystatin functionalization on MWCNTs significantly increases the water solubility, which is essential for them to be used for biological applications

The morphology of the Pure MWCNTs was characterized by SEM (Figure 4A). The clear contrast between Pure MWCNTs and MWCNTs conjugated with Nystatin indicate completion of conjugation process. Moreover, the SEM image of Pure MWCNTs shows a transparent thin film whereas after conjugation process the image (Figure 4B) obtained was not very clear due to the chemical modification of the MWCNTs.

TEM analysis (Figure 5) confirms the oxidation process (Treatment of strong acid in 3:1 ratio, $\mathrm{H}_{2} \mathrm{SO}_{4}: \mathrm{HNO}_{3}$ ) by measuring the length of MWCNTs. Length \& loading of the MWCNTs strongly depends on the duration of acid treatment. The tube length decreases \& loading increase with an increase in the duration of oxidation.

From the Table 1, it is shows that physic-chemical properties of MWCNTs after oxidation process (Treatment of strong acid in 3:1 ratio, $\mathrm{H}_{2} \mathrm{SO}_{4}: \mathrm{HNO}_{3}$ ) \& derivatization of the carboxylic acid functions get changed. ${ }^{17}$ Kaiser test was used to determine the loading of amino groups. Firstly, prepared three test solutions, (A) Ninhydrin (5\% w/v) in ethanol, (B) Phenol (4:1, w/v) in ethanol \& (C) Potassuim cyanide $(2 \%, \mathrm{v} / \mathrm{v}$, of a $1 \mathrm{mmole} /$ liter aqueous solution) in pyridine. The test was carried out by adding 2 drops of A, 1 drop of $B$ and 1 drop of $C$ to the test sample contained in a small glass test tube and then heating the tube for 2-5 minutes on a hot plate.

We selected MWCNTs treated for $10 \mathrm{hr}$ for further study as they exhibited the most convenient length \& loading (Table 1).

From the antifungal activity (MIC and MFC) (Table 2 and 3), amide f-MWCNTs, free of Nystatin, were inactive up to the maximal concentration $\left(80 \mu \mathrm{g} \mathrm{mL}^{-1}\right)$ used against all the microorganisms tested.

Conversely, Conjugation of MWCNTs-Nystatin was highly effective; indicating that activity of the Nystatin was not prevented by its covalent bonding to CNTs. 


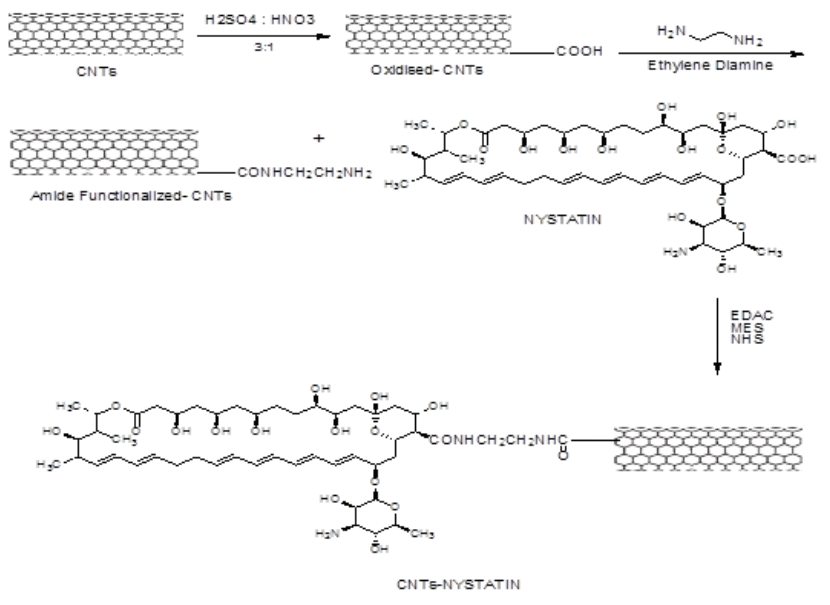

Figure 1: Schematic presentation of conjugation process of Carbon nanotubes with Nystatin.

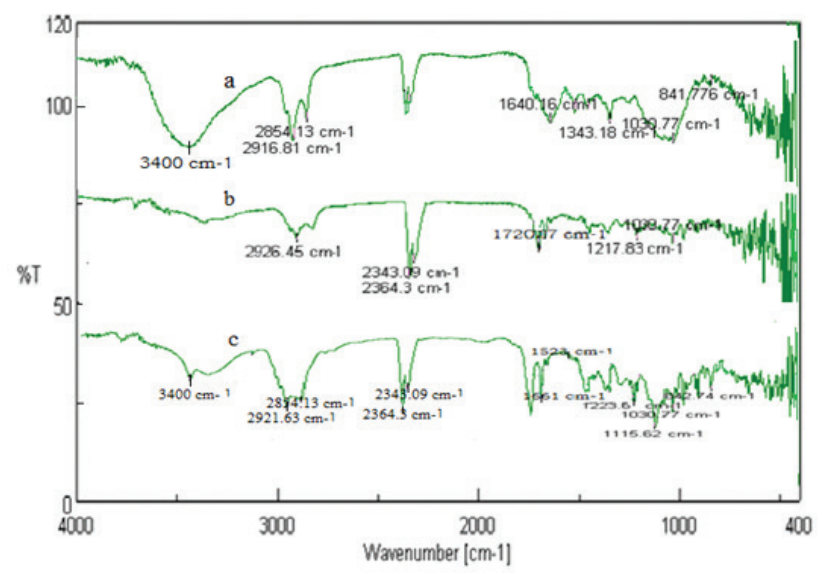

Figure 2: FT/IR Spectra of (a) Pure MWCNTs (b) OxidisedMWCNTs (c) functionalised-MWCNTs.

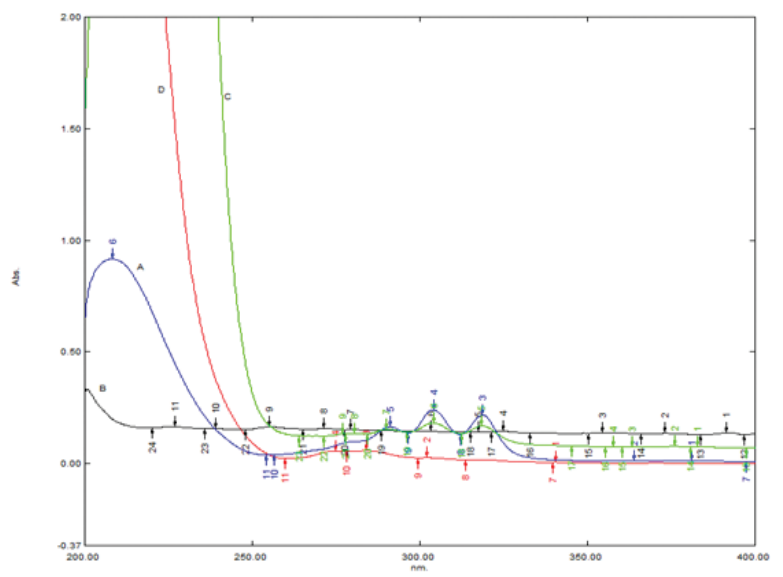

Figure 3: UV/Vis spectrum of (A) Nystatin (B) f-CNTs (C) Nystatin conjugated to MWCNTs (D) unbound Nystatin.

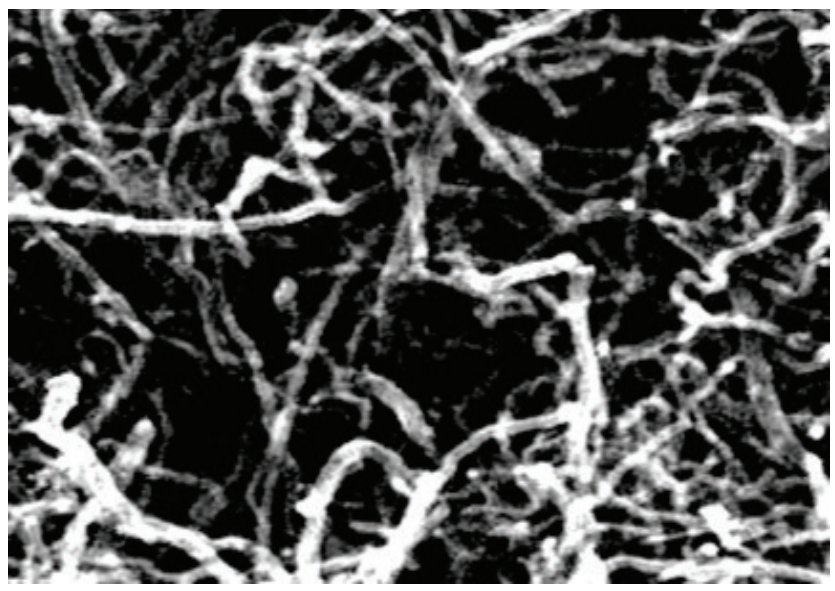

Figure 4(A): SEM Images of Pure MWCNTs.

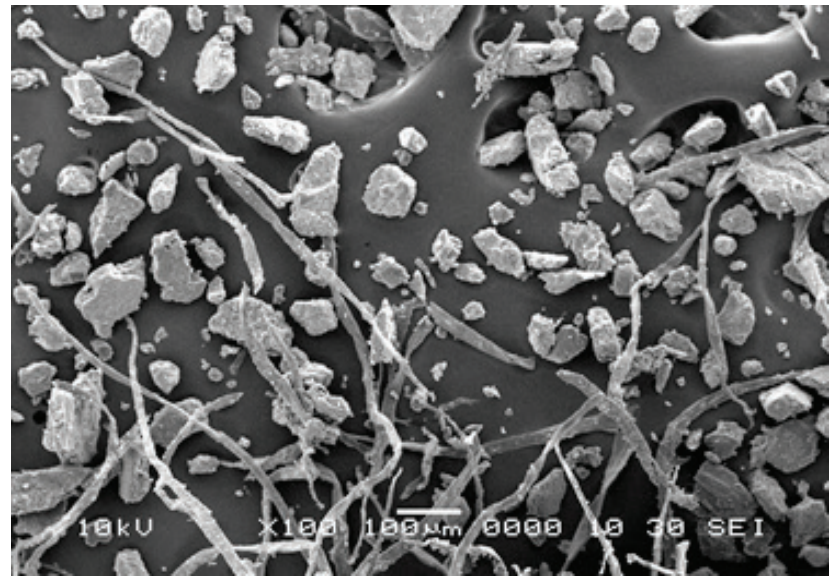

Figure 4(B): SEM Images of MWCNTs conjugated with Nystatin.

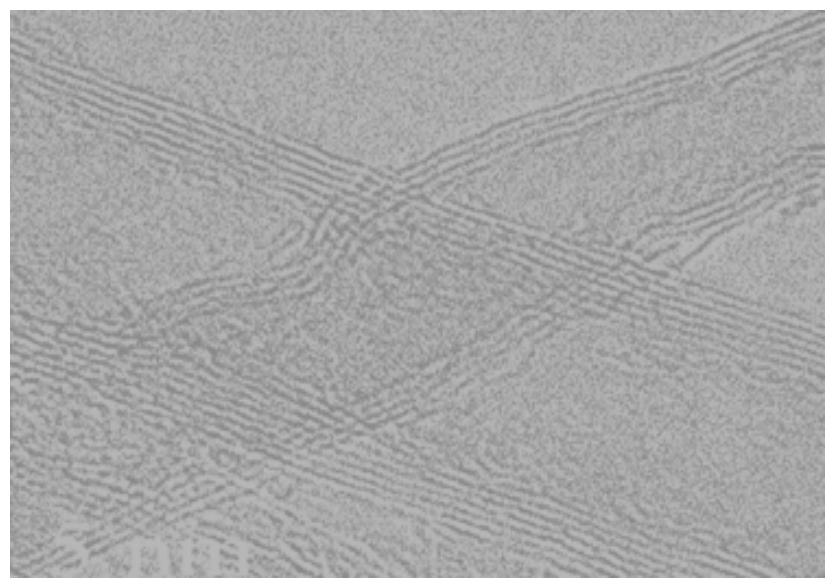

Figure 5(A): TEM images of Pure MWCNTs. 


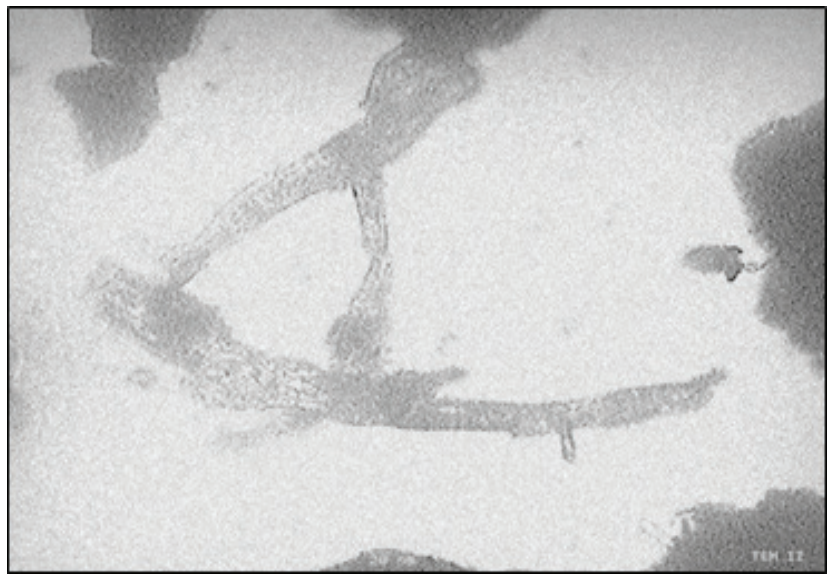

Figure 5(B):TEM images of MWCNTs after acid treatment.
Table 1: Chemico - physical properties of MWNTs after treatment with strong acid and derivatization of the

carboxylic acid functions. The result of TEM and Kaiser test for the distribution of the length and loading of functionalized carbon nanotubes

\begin{tabular}{|c|c|c|}
\hline T (hr.) & Length (nm) & $\begin{array}{c}\text { Loading } \\
\left(\mathbf{m m o l g}^{-1}\right)\end{array}$ \\
\hline 1 & $1400-4000$ & 0.09 \\
\hline 2 & $1000-2000$ & 0.16 \\
\hline 4 & $600-1400$ & 0.22 \\
\hline 6 & $200-1000$ & 0.28 \\
\hline 8 & $180-600$ & 0.38 \\
\hline 10 & $160-550$ & 0.40 \\
\hline 24 & $140-400$ & 0.46 \\
\hline
\end{tabular}

Table 2: Antifungal activity: Minimum Inhibitory Concentration (MIC)

\begin{tabular}{|c|c|c|c|}
\hline \multirow{2}{*}{ CNTs } & \multicolumn{3}{|c|}{ Minimum Inhibitory Concentration (MIC) } \\
\cline { 2 - 4 } & $\begin{array}{c}\text { Candida albicans } \\
\text { (NCIM NO-3471) }\end{array}$ & $\begin{array}{c}\text { Candida } \\
\text { parapsilosis } \\
\text { (NCIM NO-3471) }\end{array}$ & $\begin{array}{c}\text { Candida neoformans } \\
\text { (NCIM NO-3471) }\end{array}$ \\
\hline Nystatin $(\mu \mathrm{g} / \mathrm{ml})$ & 8 & 6 & 4 \\
\hline Amide $\mathrm{f}-\mathrm{CNTs}(\mu \mathrm{g} / \mathrm{ml})$ & $>80$ & $>80$ & $>80$ \\
\hline MWCNTs-Nystatin $(\mu \mathrm{g} / \mathrm{ml})$ & 6 & 4 & 2 \\
\hline
\end{tabular}

\begin{tabular}{|c|c|c|c|}
\hline \multicolumn{2}{|c|}{ Table 3: Antifungal activity: Minimum Fungicidal Concentration (MFC } \\
\hline \multirow{2}{*}{ CNTs } & \multicolumn{3}{|c|}{$\begin{array}{r}\text { Minimum Fungicidal Concentration (MFC) } \\
(\boldsymbol{\mu g} / \mathrm{ml})\end{array}$} \\
\cline { 2 - 4 } & $\begin{array}{c}\text { Candida albicans } \\
\text { (NCIM NO-3471) }\end{array}$ & $\begin{array}{c}\text { Candida } \\
\text { parapsilosis } \\
\text { (NCIM NO-3471) }\end{array}$ & $\begin{array}{c}\text { Candida neoformans } \\
\text { (NCIM NO-3471) }\end{array}$ \\
\hline Nystatin & 25 & 21 & 18 \\
\hline Amide f-CNTs & $>80$ & $>80$ & $>80$ \\
\hline MWCNTs-Nystatin & 16 & 14 & 11 \\
\hline
\end{tabular}

When the equal amounts of free \& bound drug are considered, conjugated Nystatin is definitely more potent then the free drug against the candida species..$^{10}$ the efficacy may improve because of modification in penetration ability of fragmented and conjugated MWCNT's with antifungal drug.

\section{CONCLUSION}

MWCNTs were oxidised using 3:1 ratio of $\mathrm{H}_{2} \mathrm{SO}_{4}: \mathrm{HNO}_{3}$ acids, resulting in the reduction of MWCNTs length while generating carboxylic groups. According to the results, the best length \& loading of MWCNTs was achieved for $10 \mathrm{hr}$ as they exhibited the best length \& loading. We conjugated Nystatin to MWCNTs. i.e. Amino group of MWCNTs \& Carboxylic acid group of Nystatin. From the above results, UV-Visible Spectroscopy \& Ex-vivo antifungal studies show that Nystatin successfully conjugated to the amide-functionalized Carbon nano tubes. By using CNTs (Conjugated with Nystatin), efficacy of Nystatin was increased. CNTs can be used as carrier for the Delivery of Nystatin. Results of Ex-vivo study (MIC and MFC), clearly shows that the efficacy of Nystatin was increased. The covalent linkage of Nystatin to the CNTs is an approach that may be used to modulate the therapeutic action of the Nystatin. 


\section{ACKNOWLEDGMENTS}

We appreciate the support of the PES's Modern College of pharmacy, Pune-411044 Maharashtra, INDIA. The authors thank The University of Pune for SEM, TEM analysis. Mr. Pravinkumar N. Sable, of the Modern College of Pharmacy for the FT/IR \& UV-Vis Spectroscopy. The authors also thank to Maneesh Pharmaceuticals Ltd. Mumbai, Maharashtra, INDIA for Providing us free gift sample of Nystatin drug for our research work. We appreciate comments by Dr. P. D. Chaudhari (Professor \& Principal, PES's Modern College of Pharmacy, Pune411044) \& (Dean, Department of Pharmaceutical Science, University of Pune).

\section{CONFLICT OF INTEREST}

The authors report no conflicts of interest.

\section{REFERENCES}

1. lijima S, Helical microtubules of graphitic carbon. Nature. 1991;354(6348):568.

2. Lin Y, Taylor S, Li H, Fernando SKA, Qu L, Wang W, et al. Advances towards Bio applications of carbon nano tubes. J Mater Chem. 2004;14(4):527-41.

\section{PICTORIAL ABSTRCT}

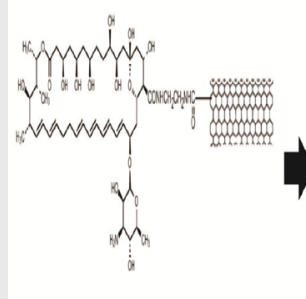

QTHSBAN

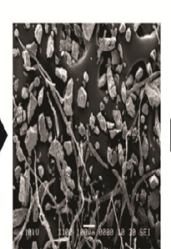

SEM Images of MWCNTs conjugated with Nystatin
Minimum Inhibitory Concentration (MIC) Candida albicans:6 $\mathrm{kg} / \mathrm{ml}$

Candida parapsilosis: $4 \mu / \mathrm{ml}$

Candida neoformans: $2 \mu \mathrm{g} / \mathrm{ml}$ 1

Minimum Fungicidal Concentration (MFC) Candida abicons: $16 \mu \mathrm{g} / \mathrm{m}$ Candida parapsilosis: $14 \mu g / m \mid$ Candida neoformans: $11 \mu g / \mathrm{ml}$
3. Nantao H, Guodong D, Hongwei Z, Jing J and Chunhai C. Efficient direct water dispersion of multi-walled carbon nano tubes by functionalization With lysine. Materials Letters. 2007;61(30):5285-87.

4. Bianco A and Prato M. Can Carbon Nano tubes Be Considered Useful Tools for Biological Applications. Adv Material. 2003;15(20):1765-68.

5. Panyam J and Labhasetwar V. Biodegradable nano particles for drug and gene delivery to cells and tissue. Advanced Drug Delivery. 2003;55(3);32947.

6. Vogelson CT. Advances in drug delivery systems, Nanotechnology, Modern Drug Discovery. 2001;4(52):49-50,

7. Daenen M, De Fouw RD, Hamers B, Janssen PGA, Schouteden K and Veld er MAJ, et al. The Wondrous World of Carbon Nano tubes, a review of current carbon nanotube Technologies. Feb2003; Eindhoven University of Technology.

8. Hirsch A. Functionalization of Single-Walled Carbon Nano tubes. Angew Chem. Int Ed. 2002;41(11):1853-59.

9. Najam-ul-Haq M, Rainer M, Schwarzenauer T, Huck CW and Bonn GK. Chemically modified carbon nano tubes as material enhanced laser desorption ionisation (MELDI) material in protein profiling. Analytica Chimica Acta. 2006;561(1-2):32

10. Li X, Peng Y, Ren J and Qu X. Carboxyl-modified single walled carbon nano tubes selectively induce human telomeric i-motif formation. Physical Sciences Chemistry. 2006;103(52):19658-663.

11. Marshall MW, Popa-Nita S and Shapter JG. Measurement of functionalised carbon Nano tube carboxylic acid groups using a simple chemical process. Carbon 2006;44(7):1137-41.

12. Mawhinney DB, Naumenko V, Kuznetsova A, Yates JT, Liu J and Smalley $\mathrm{RE}$, et al. Surface defect site density on single walled carbon nano tubes by titration. Chem Physics Lett. 2000;324(1):213-6.

\section{SUMMARY}

- Major concern of study is to improve antifungal efficacy of Nystatin which significantly improved after conjugation with functionalized multiwall carbon nanotubes.

- Functionalization of Multiwall carbon nanotubes (CNTs) are acts as nano vectors to efficient transport and translocation of therapeutic molecules to target moieties.

- Nystatin, most effective antibiotic is conjugated with CNTs via two step process of diamide-activated amidation.

- Synthesized conjugate characterized by Fourier-transform infrared spectroscopy (FT/IR), UV-Visible Spectroscopy, Scanning Electron Microscopy (SEM), \& Transmission Electron Microscopy (TEM).

- MIC (Minimum Inhibitory Concentration) and MFC (Minimum Fungicidal Concentration) results shows improved Antifungal activity. 